\title{
Forecasting auroras from regional and global magnetic field measurements
}

\author{
Kirsti Kauristie $^{1}$, Minna Myllys ${ }^{2}$, Noora Partamies ${ }^{3}$, Ari Viljanen ${ }^{1}$, Pyry Peitso ${ }^{1,4}$, Liisa Juusola ${ }^{1}$, \\ Shabana Ahmadzai ${ }^{2}$, Vikramjit Singh ${ }^{4}$, Ralf Keil ${ }^{5}$, Unai Martinez ${ }^{6}$, Alexej Luginin ${ }^{5}$, Alexi Glover ${ }^{5}$, Vicente Navarro ${ }^{5}$, \\ and Tero Raita ${ }^{7}$ \\ ${ }^{1}$ Finnish Meteorological Institute, Helsinki, Finland \\ ${ }^{2}$ University of Helsinki, Helsinki, Finland \\ ${ }^{3}$ The University Centre in Svalbard, Svalbard, Norway \\ ${ }^{4}$ Aalto University, Espoo, Finland \\ ${ }^{5}$ European Space Agency, ESOC, Darmstadt, Germany \\ ${ }^{6}$ etamax space $\mathrm{GmbH}$, Darmstadt, Germany \\ ${ }^{7}$ Sodankylä Geophysical Observatory, University of Oulu, Oulu, Finland
}

Correspondence to: Kirsti Kauristie (kirsti.kauristie@fmi.fi)

Received: 4 December 2015 - Published in Geosci. Instrum. Method. Data Syst. Discuss.: 18 January 2016 Revised: 26 May 2016 - Accepted: 31 May 2016 - Published: 28 June 2016

\begin{abstract}
We use the connection between auroral sightings and rapid geomagnetic field variations in a concept for a Regional Auroral Forecast (RAF) service. The service is based on statistical relationships between near-real-time alerts issued by the NOAA Space Weather Prediction Center and magnetic time derivative $(\mathrm{d} B / \mathrm{d} t)$ values measured by five MIRACLE magnetometer stations located in Finland at auroral and sub-auroral latitudes. Our database contains NOAA alerts and $\mathrm{d} B / \mathrm{d} t$ observations from the years 2002-2012. These data are used to create a set of conditional probabilities, which tell the service user when the probability of seeing auroras exceeds the average conditions in Fennoscandia during the coming $0-12 \mathrm{~h}$. Favourable conditions for auroral displays are associated with ground magnetic field time derivative values $(\mathrm{d} B / \mathrm{d} t)$ exceeding certain latitude-dependent threshold values. Our statistical analyses reveal that the probabilities of recording $\mathrm{d} B / \mathrm{d} t$ exceeding the thresholds stay below $50 \%$ after NOAA alerts on Xray bursts or on energetic particle flux enhancements. Therefore, those alerts are not very useful for auroral forecasts if we want to keep the number of false alarms low. However, NOAA alerts on global geomagnetic storms (characterized with $K_{p}$ values $>4$ ) enable probability estimates of $>50 \%$ with lead times of 3-12h. RAF forecasts thus rely heavily on the well-known fact that bright auroras appear during ge-
\end{abstract}

omagnetic storms. The additional new piece of information which RAF brings to the previous picture is the knowledge on typical storm durations at different latitudes. For example, the service users south of the Arctic Circle will learn that after a NOAA ALTK06 issuance in night, auroral spotting should be done within $12 \mathrm{~h}$ after the alert, while at higher latitudes conditions can remain favourable during the next night.

\section{Introduction}

According to Lilensten et al. (2008):

Space weather is the physical and phenomenological state of natural space environments. The associated discipline aims, through observations, monitoring, analysis and modelling, at understanding and predicting the state of the Sun, the interplanetary and planetary environments, and the solar and non-solar driven perturbations that affect them, and also at forecasting and nowcasting the potential impacts on biological and technological systems. 
Auroras are a harmless, fascinating feature of ionospheric space weather. They are an important factor in the business of nature tourism in polar areas. In this context there is a demand to obtain auroral forecasts with long lead times hours, days or even weeks.

The original energy source for space weather phenomena is the Sun, which emits a wide spectrum of electromagnetic waves and a continuous flow of charged particles (solar wind) to its surroundings. Rapid variations in space weather conditions (space weather storms) are associated with large-scale dynamic phenomena (coronal holes, flares and mass ejections) taking place in the solar atmosphere (corona). The first signs of solar eruptions are X-ray flares and extreme ultraviolet and radio wave bursts which reach the Earth surroundings with $\sim 8 \mathrm{~min}$ delay after their initiation. The next sign is the enhancements in energetic particle fluxes as observed, for example, at the geostationary orbit (with a few hours' delay). $\mathrm{X}$-ray flares often generate coronal mass ejections (CMEs), which are huge, massive bubble-like structures in the solar wind. It takes typically 1-2 days for a CME to propagate from its origin region to the Earth distance.

The brightest and strongest auroras and disturbances in the geomagnetic field are typically caused by CMEs. The term geoefficiency is used to characterize the capability of a structure to generate variations in the near-Earth space. Besides solar wind speed and density also the magnetic field topology of the solar wind structure is a critical factor controlling geoefficiency. Structures whose magnetic field points in the opposite direction to Earth's magnetic field at dayside magnetopause are particularly good in generating beautiful and extensive auroras. Reliable information about the magnetic topology can be achieved only by in situ measurements. For this purpose continuous solar wind measurements have been conducted at the Lagrange 1 point (L1) 1.5 million kilometres from Earth at the Sun-Earth line since the 1980s. A typical CME propagation time from L1 to Earth is $1 \mathrm{~h}$, which is - with our current scientific knowledge - also the upper limit for the lead time of reliable auroral forecasts.

Several space weather monitoring and predicting services publish alerts on X-ray flares and earthward-directed CMEs (see e.g. the service of Space Weather Prediction Center of the US National Oceanic and Atmospheric Administration (NOAA), http://www.swpc.noaa.gov/, and the Solar Influences Data Center service in Belgium, http://sidc.oma. be/). Near-real-time (NRT) information about geostationary energetic particle fluxes and global magnetic activity is also available for public use. These services thus provide useful background information for the attempts to monitor and forecast regional auroral occurrence rates.

Observations of auroral ionospheric phenomena were started in Sodankylä already during the first International Polar Year 1882-1883 (Seppinen and Pellinen, 2009). The Sodankylä Geophysical Observatory was established in 1913 by the Finnish Academy of Science and Letters (Sucksdorff et al., 2001). The Finnish Meteorological Institute started regu- lar auroral observations in Sodankylä and in some other sites in Lapland during the International Geophysical Year (19571958). In 1975 Finland became a member of the EISCAT scientific association, which built and started to operate a system of incoherent scatter radars with antennas in Troms $\varnothing$, Kiruna and Sodankylä. This triggered space research groups in Sodankylä Geophysical Observatory, Oulu University and Finnish Meteorological Institute to start a collaboration in order to conduct systematic ionospheric observations with versatile instrumentation in the surroundings of the EISCAT radars. Today's progeny from these activities is the MIRACLE network of magnetometers and auroral cameras, whose data records have been used in several studies on statistical auroral occurrence rates (Nevanlinna and Pulkkinen, 2001; Partamies et al., 2015) and on ionospheric electrodynamics linking auroras with ionospheric electric currents and geomagnetic variations (Amm et al., 2005).

In this paper we describe a concept for an auroral forecast service (hereafter called Regional Auroral Forecast, RAF), which is based on archived NOAA space weather alerts and regional magnetic field and auroral recordings. The archives are used to create a set of conditional probabilities, which tell the service user when the probability of seeing auroras exceeds the average conditions in Fennoscandia during the coming $0-12 \mathrm{~h}$. The data archives and methodology used in the development of RAF are described in Sect. 2. Results and a case study on the service performance are presented in Sect. 3. Concluding remarks and future prospects are discussed in Sect. 4.

\section{Data and methodologies}

\subsection{Magnetic field data and their connection with auroral activity}

Auroral activity is associated with variations in the geomagnetic field. During strong geomagnetic storms the amplitude of these variations can be even 4-5\% (2000 nT) of the strength of the main field in the Fennoscandian area (roughly $50000 \mathrm{nT}$ ). Typical timescales of the disturbances vary from days (duration of a storm; Gonzalez et al., 1994) to a few seconds (magnetic pulsations; Fukunishi et al., 1981). Magnetic variations are coupled with visible auroras: electron precipitation, which causes the auroral emissions by collisions with atmospheric particles, enhances also the conductivity and electric currents in the ionosphere. The ionospheric current system - according to the Biot-Savart law - generates magnetic perturbations which are measurable with ground-based magnetometers.

An easy way to characterize the intensity of space weather variations is to use a proxy, which describes the strength of ionospheric and magnetospheric currents and is based on measurements by a global and/or local network of groundbased magnetometers. The global $K_{p}$ index is one of the 


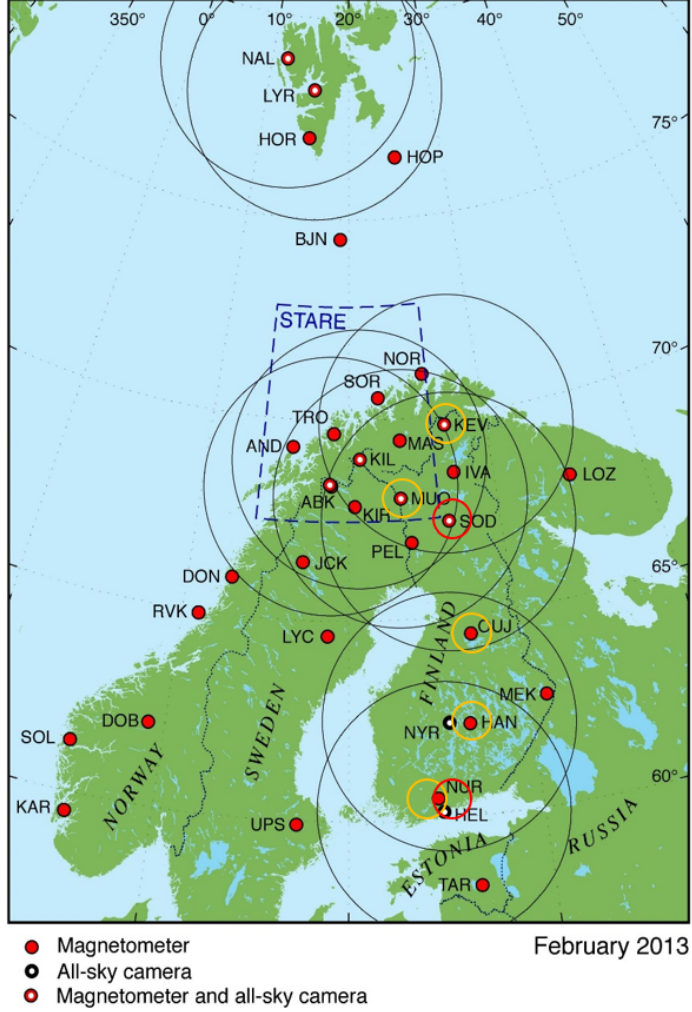

Figure 1. Stations of the MIRACLE network. The fields of view of auroral cameras are shown with black circles and the observing area of the bistatic STARE radar (operated 1997-2005) with the rectangle (dashed lines). Magnetometer stations used in the RAF and Auroras Now! services are shown with the small red and orange circles, respectively.

most widely used proxies in this area. It is defined to be the mean value of the disturbance levels in the horizontal magnetic field component observed at 13 selected, sub-auroral stations (Bartels et al., 1939). The index has $3 \mathrm{~h}$ time resolution, and its value is given in a range $0-9$ according to a station-specific, quasi-logarithmic scale. While $K_{p}$ describes nicely the overall space weather activity, observations of the local magnetic field time derivative $(\mathrm{d} B / \mathrm{d} t)$ with high time resolution are a more useful way to support regional auroral monitoring services. This linkage is utilized in an already existing public auroral monitoring system Auroras Now! (http://aurora.fmi.fi), which was designed as a Space Weather Applications Pilot Project with some support of the European Space Agency (ESA) in the early 2000s. The service has become popular with thousands of daily visitors during wintertime.

The Auroras Now! service is based on NRT data from the Magnetometers-Ionospheric Radars-All-sky Cameras Large Experiment (MIRACLE) network of auroral cameras and magnetometers (http://space.fmi.fi/MIRACLE, cf. Fig. 1 and Table 1). In the original version of Auroras Now! $\mathrm{d} B / \mathrm{d} t$ values from two observatories - Nurmijärvi (NUR, sub-auroral
Table 1. Magnetometer stations used in the Auroras Now! and RAF services and the corresponding $\mathrm{d} B / \mathrm{d} t$ threshold for enhanced probability of aurora occurrence. Magnetic latitude (MLAT) is given in the frame of corrected geomagnetic coordinates.

\begin{tabular}{llccc}
\hline Code & Name & $\begin{array}{c}\text { Geographical } \\
\text { coordinates }\end{array}$ & $\begin{array}{c}\text { MLAT } \\
\text { degree N }\end{array}$ & $\begin{array}{c}\mathrm{d} B / \mathrm{d} t \\
\text { threshold }\end{array}$ \\
\hline NUR & Nurmijärvi & $60.50^{\circ} \mathrm{N}, 24.65^{\circ} \mathrm{E}$ & $56.9^{\circ}$ & $0.30 \mathrm{nT} \mathrm{s}^{-1}$ \\
HAN & Hankasalmi & $62.25^{\circ} \mathrm{N}, 26.60^{\circ} \mathrm{E}$ & $58.7^{\circ}$ & $0.35 \mathrm{nT} \mathrm{s}^{-1}$ \\
OUJ & Oulujärvi & $64.52^{\circ} \mathrm{N}, 27.23^{\circ} \mathrm{E}$ & $61.0^{\circ}$ & $0.42 \mathrm{nT} \mathrm{s}^{-1}$ \\
SOD & Sodankylä & $67.37^{\circ} \mathrm{N}, 26.63^{\circ} \mathrm{E}$ & $63.9^{\circ}$ & $0.50 \mathrm{nT} \mathrm{s}^{-1}$ \\
MUO & Muonio & $68.02^{\circ} \mathrm{N}, 23.53^{\circ} \mathrm{E}$ & $64.7^{\circ}$ & $0.52 \mathrm{nT} \mathrm{s}^{-1}$ \\
KEV & Kevo & $69.76^{\circ} \mathrm{N}, 27.01^{\circ} \mathrm{E}$ & $66.3^{\circ}$ & $0.57 \mathrm{nT} \mathrm{s}^{-1}$ \\
\hline
\end{tabular}

latitudes) and Sodankylä (SOD, auroral latitudes) - were monitored continuously. Enhanced opportunity to see auroras is empirically defined to take place when the hourly maximum of $\mathrm{d} B / \mathrm{d} t$ exceeds $0.3 \mathrm{nT} \mathrm{s}^{-1}$ in Nurmijärvi and $0.5 \mathrm{nT} \mathrm{s}^{-1}$ in Sodankylä. More exactly, the hourly maxima of time derivatives of $x$ and $y$ components (geographic north and east components with $1 \mathrm{~min}$ time resolution) are calculated and the larger one is compared with the threshold. The performance of Auroras Now! has been evaluated by comparing Sodankylä auroral and magnetometer observations during the season from 1 November 2003 to 31 March 2004 (Mälkki et al., 2006). The analysis shows that in $86 \%$ of the cases when the $\mathrm{d} B / \mathrm{d} t$ threshold was exceeded also auroras were observed. In the $13 \%$ of the cases when Auroras Now! failed to spot the auroras, the intensities were typically dim or even below the sensitivity of human eye.

RAF uses the same empirical rules between auroral occurrence and $\mathrm{d} B / \mathrm{d} t$ that were used in Auroras Now! The threshold values for the magnetometer stations depend on the magnetic latitudes; for additional stations used in RAF they are determined by linear inter- and extrapolation from the corresponding values of Nurmijärvi and Sodankylä. The statistical study of Finnish all-sky camera recordings from years 1973-1997 by Nevanlinna and Pulkkinen (2001) shows that assuming a linear trend in the auroral occurrence probability according latitude is a good approximation at magnetic latitudes $63-70^{\circ}$. At latitudes below $63^{\circ}$ the evidence for a linear trend is less clear, but as all-sky observations from these latitudes are scarce in the analysed database, we use the linear relationship there also as the first approximation. The RAF stations with their coordinates and $\mathrm{d} B / \mathrm{d} t$ threshold values are listed in Table 1. Stations KEV and MUO are at latitudes poleward of the Arctic Circle $\left(66.56^{\circ} \mathrm{N}\right)$ and under the average auroral oval during moderate activity levels. Stations OUJ, HAN and NUR are at sub-auroral latitudes where high $\mathrm{d} B / \mathrm{d} t$ values are recorded only during space weather storms. 
Table 2. The number of NOAA alerts used in the study. For $K_{p}=4-8$ the four values in the given sums are the number of the events which took place in the local time bins of dawn, dusk, night and noon (for more details see text).

\begin{tabular}{ll}
\hline Alert & No. \\
\hline ALTEF3 & 1459 \\
ALTK04 & $350+249+129+267=995$ \\
ALTK05 & $177+92+54+126=449$ \\
ALTK06 & $71+40+21+63=195$ \\
ALTK07 & $16+11+12+20=59$ \\
ALTK08 & $2+2+6+7=17$ \\
ALTK09 & 5 \\
ALTPC0 & 31 \\
ALTPX1 & 92 \\
ALTPX2 & 43 \\
ALTPX3 & 19 \\
ALTPX4 & 1 \\
ALTTP2 & 377 \\
ALTTP4 & 196 \\
ALTXMF & 159 \\
\hline
\end{tabular}

\subsection{Statistical relationship between regional magnetic field variations and space weather alerts}

Forecasts of auroral activity in RAF are based on statistical relationships between space weather alerts which describe solar and global activity and $\mathrm{d} B / \mathrm{d} t$ values measured at the RAF magnetometer stations. In the development work we used archives of NRT alerts by NOAA, Halo-CME alerts by SIDC and Finnish Meteorological Institute's (FMI's) alerts for enhanced magnetic variability based on ACE data (available with the Auroras Now! service). We concentrate on the results based on NOAA alerts (issued 2002-2012, cf. Table 2) as they appeared to be most useful for prediction purposes.

In the statistical analysis we sought answers to questions such as the following: what is the probability of measuring $\mathrm{d} B / \mathrm{d} t>A$ at station $\mathrm{B}$ with the alert of type $\mathrm{C}$ issued $T$ hours earlier? Here values of $A$ and corresponding stations B are those listed in Table 1 . The value $T$ varies in the range 1-48, and the different alert types (C) are described below. In practice the analysis was conducted in the following steps:

1. Constructing a summary matrix on the NOAA alerts: each row in the matrix corresponds to $1 \mathrm{~h}$ during the years 2002-2012. Each alert type has one dedicated column in the row. If that alert is issued during the hour of the row, the variable in the column is 1 ; otherwise it is zero.

2. Constructing a summary matrix on the hourly maxima in $\mathrm{d} B / \mathrm{d} t$ values recorded at the RAF magnetometer stations: also this matrix has values 1 (in the case of $\mathrm{d} B / \mathrm{d} t$ threshold excess) or 0 (no threshold excess).
3. Determining statistical relationships between the parameters in the two matrices described above: for each alert type the hours of issuance were searched and the values in the $\mathrm{d} B / \mathrm{d} t$ matrix for the following $48 \mathrm{~h}$ were inspected. For these $48 \mathrm{~h}$ and for each RAF magnetometer stations the ratio $W / V$ was determined, where $W$ is the number of hours when the threshold for auroras was exceeded and $V$ is the total number of hours in the analysis (i.e. the number of issuances of the analysed alert type during the 10-year period). The combined effect of subsequent alerts was ignored in the analysis as alerts with less than $48 \mathrm{~h}$ separation were handled as independent separate cases.

4. Identifying those NOAA alert types which yield $W / V$ values equal to or larger than 0.5 .

5. Refining the analysis of step 3 by binning the data points according to magnetic local time (MLT) of the RAF stations at issuance moment and by studying the combined effect of some of the most influential alerts. Four bins were used in the local time binning: noon (06:00-12:00 UT), night (18:00-24:00 UT), dawn (00:00-06:00 UT) and dusk (12:00-18:00 UT). (Note: for the MIRACLE local time sector magnetic local time $\sim \mathrm{UT}+2.5 \mathrm{~h}$.)

The NOAA archives contain the following types of alerts:

- Solar X-ray flare alerts (ALTXMF) are issued when the solar X-ray flux exceeds the M5 level $\left(5 \times 10^{-5} \mathrm{~W} \mathrm{~m}^{-2}\right.$, at wavelengths $0.1-0.8 \mathrm{~nm}$ and measured at the geostationary distances).

- Alerts on enhanced proton fluxes at the geostationary distances (ALTPX1-ALTPX4) are issued when the integral flux of protons with energies above $10 \mathrm{MeV}$ exceeds values $10,100,1000$, or $10000 \mathrm{pfu}$ (particle flux units).

- Alerts on enhanced electron fluxes at the geostationary distances (ALTEF3) are issued when the integral flux of electrons with energies above $10 \mathrm{MeV}$ exceeds a value 1000 pfu.

- Solar Radio Burst alerts (ALTTP2, ALTTP4) are issued in the cases of enhancements in Type II or Type IV radio emissions with frequencies $<15 \mathrm{MHz}$. Emissions are caused by accelerated electrons in the context of solar wind shocks and CMEs.

- Alerts on enhanced global geomagnetic activity (ALTK04-ALTK09) are issued when the $K_{p}$ estimate by the Wing $K_{p}$ model (Wing et al., 2005) exceeds values $4-9$.

In the following discussion we use the $W / V$ value (in \%) as a proxy for the auroral occurrence probability, although strictly 


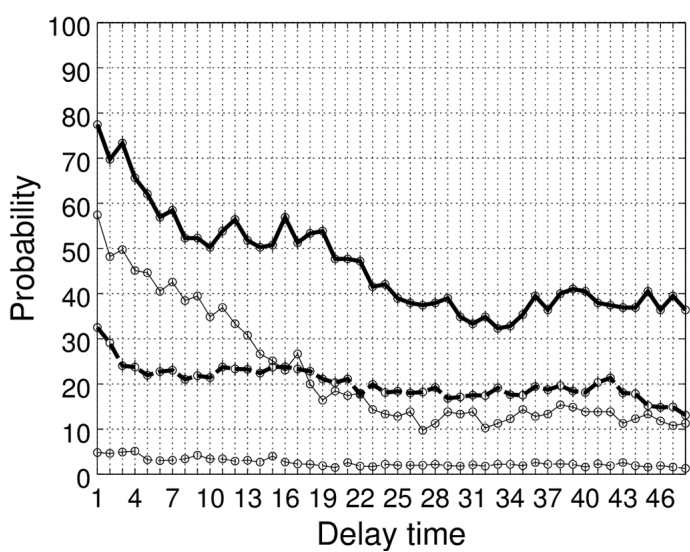

Figure 2. $W / V$ values (in \%) for stations KEV (thick lines) and NUR (thin lines) during $48 \mathrm{~h}$ after the issuance of ALTK06 (solid lines) and ALTK04 (dashed lines). $W$ is the number of cases with $\mathrm{d} B / \mathrm{d} t$ excess above the threshold for enhanced auroral occurrence. $V$ is number of ALTK06 (195) and ALTK04 (995) issued during the years 2002-2012.

speaking this value represents the probability of $\mathrm{d} B / \mathrm{d} t$ excess above the given threshold. Figure 2 is an example plot on the $W / V$ value for stations KEV and NUR during the next $48 \mathrm{~h}$ after the NOAA ALTK04 and ALTK06 issuance times. According to this plot the probability of enhanced auroral occurrence is above $50 \%$ at KEV during $\sim 10 \mathrm{~h}(0 \mathrm{~h})$ after the issuance of ALTK06 (ALTK04). At the sub-auroral station NUR the probability stays above $50 \%$ only for the first hour after the ALTK06 issuance time.

\section{Results}

\subsection{Analysis of $W / V$ curves}

We begin the investigation of the $W / V$ curves with the ALTXMF case because X-ray flares give the first signs of forthcoming space weather activity, and thus they have potential to support forecasts with the longest feasible lead times. Figure 3 shows the probability curve of ALTXMF for stations KEV, OUJ and NUR. In this case we extend the axis of delay times up to $120 \mathrm{~h}$ in order to take into account also the impact of slowly propagating CMEs. Error bars in Fig. 3 (and in the subsequent similar figures) are determined with the standard deviation for Poisson distribution, i.e. $\varepsilon=(\sqrt{(W)})^{-1}$ $(100 \mathrm{~W} / \mathrm{V})$. ALTXMF appears not to be a reliable enough way to forecast enhanced auroral occurrence as all probability values in Fig. 3 are below $50 \%$. The impact of CMEs is visible as a moderate increase in $W / V$ values ( $~ 15 \%$ units) for delay times $37-80 \mathrm{~h}$ in the curves of sub-auroral stations OUJ and NUR, where the average level of magnetic variability is low. At KEV the baseline level of $W / V$ is so high ( $\sim 20-30 \%)$ that no specific CME signatures can be distinguished from the background activity. In general, the feature

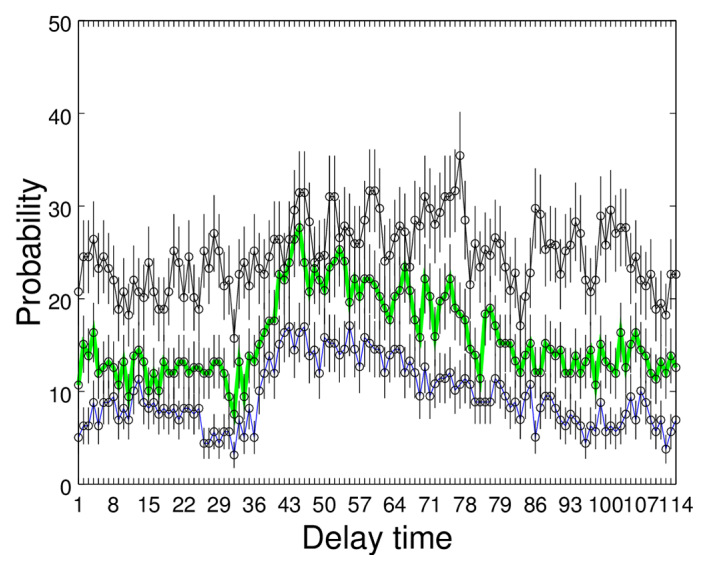

Figure 3. $W / V$ values (in \%) for stations KEV (black), OUJ (green) and NUR (blue) during $120 \mathrm{~h}$ after the issuance of ALTXMF. $W$ is the number of cases with $\mathrm{d} B / \mathrm{d} t$ excess above the threshold for enhanced auroral occurrence. $V$ is number of ALTXMF (159) issued during the years 2002-2012.

of ALTXMF $W / V$ curves staying at values $<50 \%$ can be explained with the different propagation speeds of CMEs and two factors limiting their geoefficiency: not all flares generate CMEs, which are directed towards the Earth, and not all CMEs have the correct magnetic topology to generate high $\mathrm{d} B / \mathrm{d} t$ values.

The $W / V$ curves of solar radio bursts (ALTTP2, ALTTP4) and those for energetic proton and electron enhancements (ALTEF3, ALTPX1-ALTPX4) gave similar results as those of ALTXMF (no values exceeding 50\%). The alerts on global geomagnetic activity (ALTK04-ALTK09), however, yielded more promising results. As explained in Sect. 2.2, further improvement is achieved by binning the alerts according to their issuance times. The response at RAF stations depends on their local time sector. High $W / V$ values are achieved for those delay times which correspond to the situation where RAF stations are around midnight. UT binning was applied only for ALTK04-ALTK06; for ALTK07 the total number of alerts is too small to allow MLT binning for meaningful statistical analysis. Also for ALTK08 and ALTK09 we still need longer data archives before any $W / V$ curves can be derived, but on the other hand the curves of ALTK07 already can give a relatively good picture of the case of exceptionally strong space weather storms. Thus in the operational RAF service probability curves from the combined ALTK07, ALTK08 and ALTK09 are used.

Like mentioned in Sect. 2.2, the NOAA K-alerts and consequently also the RAF forecasts are based on the Wing $K_{p}$ model, which in some cases may result in too optimistic estimates on auroral occurrence rates. Bala and Reiff (2014) have tested the performance of Wing $K_{p} 1 \mathrm{~h}$ forecast with real-time output values collected during a test period of 22 months (April 2011-February 2013). This study shows that the Wing $K_{p}$ approach has some tendency to overesti- 


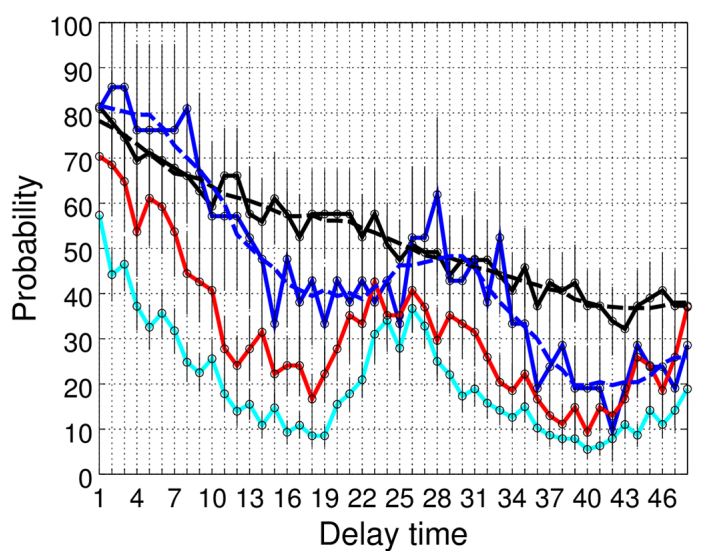

Figure 4. $W / V$ values (in \%) of station MUO for ALTK04 (cyan), ALTK05 (red), ALTK06 (blue) and for ALTK07 (black). The curve for ALTK07 is based on all data points, while for the other activity levels only the points of nighttime bin were used (for the number of data points, see Table 2). The dashed lines represent smoothed curves (seven-point running averages) for ALTK06 and ALTK07, which are used in the operational RAF service.

mate $K_{p}$ values during enhanced activity. In the test data set of 15960 time instants the Wing approach claimed the $K_{p}$ to be equal to or more than 4 in 1222 cases. A check against the official $K_{p}$ values reveals that 335 of these were false alarms (i.e. the real $K_{p}$ was $<4$ ).

Figures 4 and 5 show the $W / V$ curves of MUO and HAN for ALTK04-ALTK06 (for the night bin) and for ALTK07 (all points). The $W / V$ curves of MUO and KEV are mainly similar (latter not shown), and they describe the $\mathrm{d} B / \mathrm{d} t$ activity at auroral latitudes: the threshold of $50 \%$ is exceeded already after ALTK04 although only for the first hour. In the case of ALTK05, occurrence of high $\mathrm{d} B / \mathrm{d} t$ values lasts some $7 \mathrm{~h}$ after the alert; for ALTK06 high $\mathrm{d} B / \mathrm{d} t$ values were recorded with $50 \%$ probability for the delay hours 13 and 26-30. After ALTK07, enhanced $\mathrm{d} B / \mathrm{d} t$ activity lasts some $26 \mathrm{~h}$. The $W / V$ curves of HAN have the same features as those of NUR (not shown). At the sub-auroral latitudes occurrence rates of high $\mathrm{d} B / \mathrm{d} t$ values with auroral occurrence probablity $>50 \%$ appear only for ALTK06 or higher and for delays of $1-11 \mathrm{~h}$. In the case of ALTK07, enhanced activity persists for $13-15 \mathrm{~h}$. The $W / V$ curves of OUJ (not shown) are similar to those of HAN and NUR otherwise, but the $50 \%$ threshold of occurrence of high $\mathrm{d} B / \mathrm{d} t$ values is exceeded already at the activity level of ALTK05, although only during the first hour after the alert. The most important conclusion from Figs. 4 and 5 is that at auroral latitudes the occurrence rates for high $\mathrm{d} B / \mathrm{d} t$ are close to $50 \%$ still during the next night after the issuance of ALTK06 or ALTK07, while at the sub-auroral stations the $W / V$ values drop below $50 \%$ already after a delay of $12-16 \mathrm{~h}$.

Figure 6 demonstrates the effect of UT binning in $W / V$ curves for MUO after ALTK06. Again, similar be-

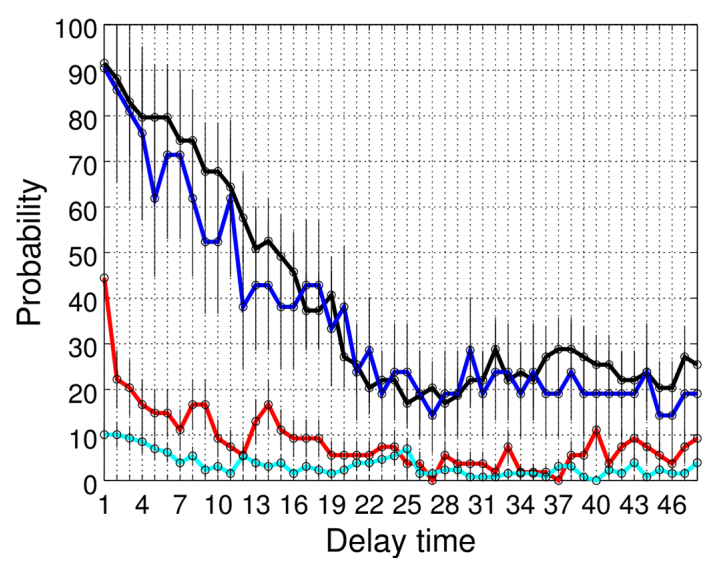

Figure 5. $W / V$ values (in \%) of station HAN for ALTK04 (cyan), ALTK05 (red), ALTK06 (blue) and for ALTK07 (black). The curve for ALTK07 is based on all data points, while for the other activity levels only the points of nighttime bin were used (for the number of data points, see Table 2).

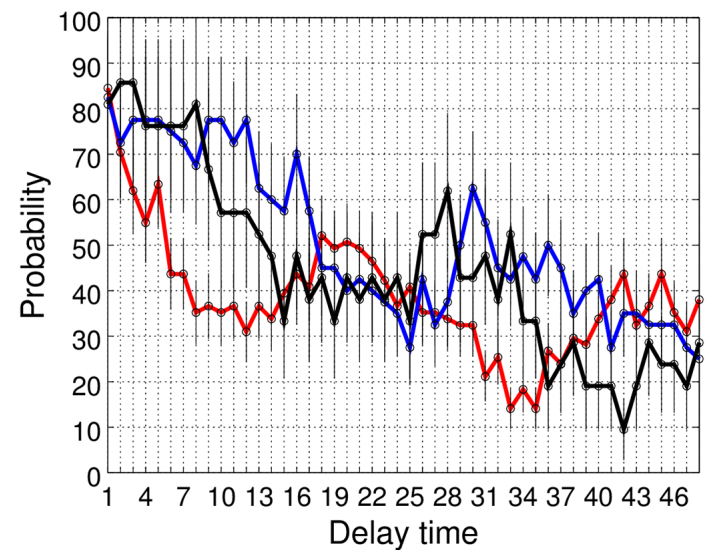

Figure 6. $W / V$ values (in \%) of station MUO for ALTK06 and the UT bins of dawn (red), dusk (blue) and night (black).

haviour appears in the $W / V$ curves of KEV. The curves of night and dusk sector issuance times suggest that for the coming night $V / W$ values are well above $50 \%$. ALTK06 issuance around noon also indicates $\geq 60 \%$ auroral probabilities for the coming night (curves not shown). In the case of dawn sector issuances the ongoing night is clearly more favourable for auroral spotting than the following night. In other words if there is already high magnetic activity in the beginning of the dark time, it will likely continue during the nearest night hours. On the other hand, high morning activity does not strongly indicate that the next night $\sim 12 \mathrm{~h}$ later will still show auroral displays.

\subsection{Description of the operational RAF service}

The RAF service has been developed with ESA funding in the space weather segment of ESA's Space Situational 

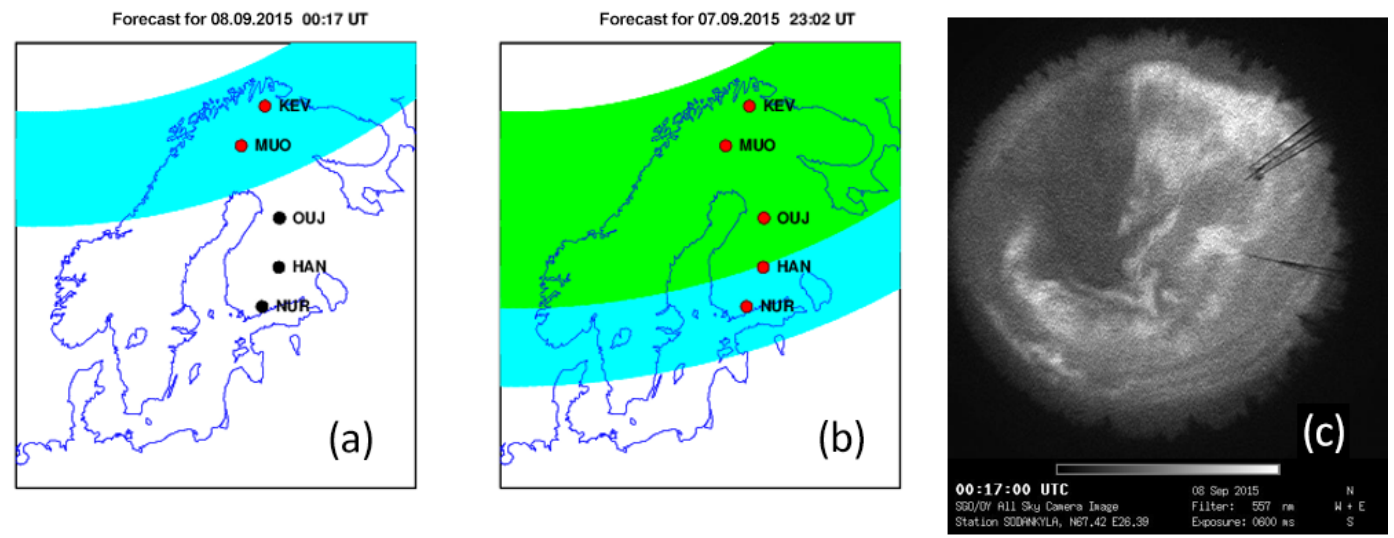

Figure 7. RAF forecasts on auroral occurrence probability (a, b) for a couple of time instants around midnight on 7-8 September 2015 and an example image from the Sodankylä auroral camera station from the same time period (c). The forecasts were published at (a) 15:17 UT and (b) 17:02 UT. Cyan (green) colour gives regions with $>50 \%(>70 \%)$ probability of auroral sightings.

Awareness programme during years 2013-2015. The service has two parts: the nowcast service which characterizes prevailing auroral occurrence probability with the same approach as Auroras Now! and the forecast service which uses the above described RAF approach. In both parts the regions of enhanced auroral occurrence probabilities are shown as bands of cyan $(W / V>50 \%)$ or green $(W / V>70 \%)$ colour overlaid on the map of Fennoscandia. These bands are positioned at the latitudes of $\pm 2^{\circ}$ around the RAF stations where the forecast $\mathrm{d} B / \mathrm{d} t$ exceeds the threshold of enhanced probability of auroral occurrence (for an example, see Fig. 7). The forecast service checks the latest NOAA alerts every $15 \mathrm{~min}$. If alerts of the correct type (ALTK04-09, ALTPX) were issued during the previous $15 \mathrm{~min}$, the service would check the corresponding $W / V$ curves with UT binning for delays of $T_{0}+3, T_{0}+6, T_{0}+9$ and $T_{0}+12$ (where $T_{0}$ is the alert issuance hour) and draws the forecast maps accordingly.

Figure 7 presents an example of RAF performance on the evening of 7 September 2015. On that day $K_{p}$ values started to increase after noon so that the values for the $3 \mathrm{~h}$ periods ending at UT times 15:00, 18:00, 21:00, and $24: 00$ were $4.67,6.33,5.67$, and 6.33 , respectively. The first maps forecasting auroral activity appeared to the RAF service at 15:17 UT (at 18:17 LT - local time). The maps for $T_{0}+3, T_{0}+6$, and $T_{0}+9$ (i.e. until 00:17 UT) showed bands of cyan colour above KEV and MUO stations (cf. Fig. 7a). Roughly $2 \mathrm{~h}$ later at 17:02 UT, RAF made a radical correction in its forecasts: the forecast maps showed auroras to all latitudes for all lead times $\left(T_{0}+3-\right.$ $T_{0}+12$ ), and even with $>70 \%$ probability for latitudes above KEV, MUO and OUJ until 02:02 UT (cf. Fig. 7b). This time the correction was successful: beautiful auroras were observed at several sites all over Finland. The photograph archives maintained by the Finnish Ursa Association of amateur astronomers (http://www.taivaanvahti.fi/observations/ browse/list/1120892/observation_start_time) contain photos of auroral displays until 00:30 UT (03:30 LT) on 8 September 2015. The auroral camera of MIRACLE network in Sodankylä also captured spectacular auroras for several hours during that night (Fig. 7c).

Test versions of RAF have been operated at the servers of ESA and the Finnish Meteorological Institute since May 2014. Validation studies with auroral observations from the Ursa service and by auroral cameras of Japanese and Finnish research groups have revealed that the performance of RAF is on a satisfactory level in the case of strong, extensive auroras (activity also at sub-latitudes), but it can miss auroral displays occurring at high latitudes during moderate activity. The $W / V$ curves of KEV in Figs. 2 and 3 help in understanding this result. In both figures the baseline level of high $\mathrm{d} B / \mathrm{d} t$ occurrence rate, i.e. the level where $W / V$ values settle at long delay times, is around $20-30 \%$ for KEV. This means that at auroral latitudes nice auroral displays can take place relatively often, although no significant global activity is ongoing. Giving case-by-case forecasts of such displays is challenging since they most likely manifest the stochastic part of solar wind-geospace interactions related to turbulence in the solar wind (Pulkkinen et al., 2006). Anyways, it is possible to estimate the locations of the average auroral oval boundaries with statistical oval models. Sigernes et al. (2011) present a method for deriving the oval location for different $K_{p}$ levels. The method is based on oval models derived from optical and particle precipitation data (Starkov, 1994; Zhang and Paxton, 2008). We have compared the oval locations by the $\mathrm{d} B / \mathrm{d} t$ approach used in RAF to those by the Starkov oval with data from a test period (5 May-28 October 2014). This comparison study suggests that these two approaches complement each other nicely: the tool by Sigernes et al. (2011) guides users to appropriate latitudes during moderate activity, while RAF gives a more realistic representation on oval dynamics during strong $K_{p}$ activity. 


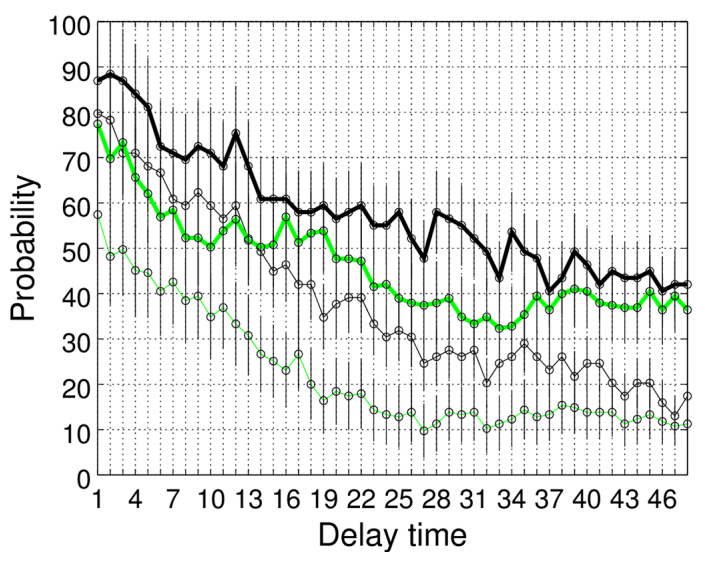

Figure 8. $W / V$ values (in \%) of station KEV (black) and NUR (green) for the special case of ALTPX* preceding ALTK06 (thick lines) and for the case of all ALTK06 events. The number of data points in the bin of special cases is 69 .

\section{Concluding remarks and future prospects}

We have used the connection between auroral sightings and rapid geomagnetic field variations in the development of the Regional Auroral Forecast (RAF) service. The service is based on statistical relationships between NRT alerts issued by the NOAA Space Weather Prediction Center and $\mathrm{d} B / \mathrm{d} t$ values measured by five MIRACLE magnetometer stations located in Finland at auroral and sub-auroral latitudes. Our database contains NOAA alerts and $\mathrm{d} B / \mathrm{d} t$ observations from the years 2002-2012. Magnetometer data have been used instead of direct auroral observations when constructing the statistics because processing numerical data is simpler than recognizing auroras from images, whose quality can occasionally suffer from cloudiness and moonlight contamination. The close linkage of auroral and magnetic activity has been utilized also in the NRT service by Johnsen (2013), which associates the latitudes of enhanced auroral occurrence rates with regions where auroral electrojets are strongest. Another way to overcome the complications in statistical analysis of auroral images is to construct the oval model with the help of auroral particle precipitation measurements by polar-orbiting satellites. This pathway has been used in the OVATION Prime empirical model, which is available, for example, on the home page of NOAA Space Weather Prediction Center and is based on particle data from the Defense Meteorological Satellite Program (DMSP).

Our statistical analyses reveal that NOAA alerts on X-ray bursts or on energetic particle flux enhancements cannot be used in the forecasts if only probability values above $50 \%$ for successful auroral spotting are used in the service. However, NOAA alerts on global geomagnetic storms (characterized with $K_{p}$ values $>4$ ) enable probability estimates of $>50 \%$ with lead times of $1-12 \mathrm{~h}$. RAF forecasts thus rely heavily on the well-known fact that bright auroras appear during ge-

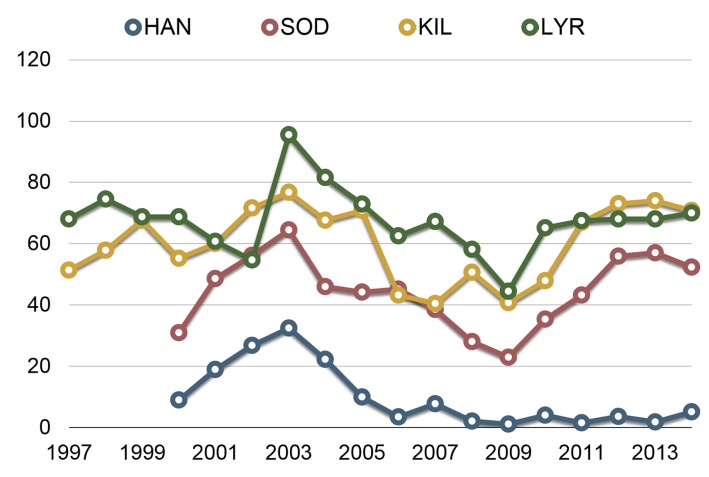

Figure 9. Occurrence probability of auroras at MIRACLE auroral camera stations with the following magnetic latitudes: HAN 59 ; SOD $64^{\circ}$; KIL $66^{\circ}$; LYR $75^{\circ}$. Probabilities are based on visual inspections of quick look data (keograms, one image per night). The annual number of nights with auroras was normalized with the number of nights when the camera was operational (updated version of Fig. 9 by Pulkkinen et al., 2011).

omagnetic storms. The additional new piece of information which RAF brings to the previous picture is the knowledge on typical storm durations at different latitudes. For example, the service users southward of the Arctic Circle will learn that after a NOAA ALTK06 issuance, auroral spotting should be done within $12 \mathrm{~h}$ after the alert, while at higher latitudes conditions can remain favourable still during the next night.

We have handled the different NOAA alert types as separate independent cases, which is a limitation to be overcome in future studies with longer records of NOAA alerts. It is very likely that sequences of several subsequent $K_{p}$ alerts or their combinations (e.g. with alerts on enhanced energetic particle fluxes) produce different probability curves for high $\mathrm{d} B / \mathrm{d} t$ values than single alerts. The probability curves of Fig. 8 support this anticipation: the probabilities for the special case, where ALTK06 has been preceded (within 24h) by an alert on enhanced proton fluxes (ALTPX*), are larger than those for the case of all ALTK06 alerts. This feature is taken into account in RAF, but obviously accounting also for other alert combinations would improve the performance of the service as soon as enough archived alert data have been accumulated to test this hypothesis.

Our approach is not very useful in the attempts to forecast auroras at high latitudes during non-storm times. Statistical analysis of MIRACLE all-sky camera data shows that during the best years of auroral activity (some 2-3 years after sunspot maxima) the occurrence rates are $60-75 \%$ at stations under the auroral oval (i.e. at magnetic latitudes 64$75^{\circ}$; stations SOD, KIL and LYR in Fig. 9). Comparing these values to the threshold which we use in RAF for enhanced auroral activity (occurrence probability $>50 \%$ ) reveals that cloudiness forecasts provide at auroral latitudes more useful information for auroral spotting than RAF statistics. At subauroral latitudes an announcement of enhanced probability 
by RAF can be interpreted to represent conditions which prevail at auroral latitudes during the most favourable years in the solar cycle. With the latitudinal coverage of MIRACLE all-sky and magnetometer observations (Fennoscandian sector), we conclude that the auroral oval latitudes in this context correspond roughly to magnetic latitudes $64-75^{\circ}$, while latitudes below MLAT 61 represent sub-auroral regions.

The threshold values which we use for $\mathrm{d} B / \mathrm{d} t$ as an implication of enhanced auroral activity may be adjusted in the future, when we have gathered more experience in aurora data analysis with advanced machine-learning methods (Rao et al., 2014; Syrjäsuo and Partamies, 2011). Finding optimal values for automatic recognition will not be straightforward since there is some variability in the user requirements (photographing versus naked-eye observations). The threshold values used in RAF come as legacy from the Auroras Now! service, which was designed during the years 2003-2005. These thresholds usually deserve their place as the first approximation, but as nowadays the user community includes more auroral photographers with high-end camera equipment than 10 years ago, the detection threshold values may need some lowering in the future RAF upgradings. Long, homogeneous and validated records of ionospheric observations, like those provided by the Sodankylä research station and the surrounding MIRACLE network, will be crucial input for such upgrading work.

\section{Data availability}

Space weather alerts are available via the service of Space Weather Prediction Center of the US National Oceanic and Atmospheric Administration (NOAA) (http://www. swpc.noaa.gov/, old archives at http://legacy-www.swpc. noaa.gov/alerts/archive.html) and via the Solar Influences Data Center service in Belgium (http://sidc.oma.be/). The NOAA OVATION auroral forecast is available at http://www. swpc.noaa.gov/products/aurora-30-minute-forecast. The auroral forecast service maintained by Kjell Henriksen Observatory (Svalbard, Norway) is available at http:// kho.unis.no. The Auroras Now! service for NRT monitoring of auroras in Finland is available at http:// aurora.fmi.fi. The Ursa Astronomical Association (Finland) maintains a browsing system for auroral photos at http://www.taivaanvahti.fi/observations/browse/list/ 1120892/observation_start_time. Auroral and magnetometer data by MIRACLE network can be requested from http: //space.fmi.fi/MIRACLE.

Acknowledgements. The authors thank the Space Weather Prediction Center of NOAA and SIDC for providing access to their archived space weather alerts.

The MIRACLE network is operated as an international collaboration under the leadership of the Finnish Meteorological Institute. The IMAGE magnetometer data are collected as a joint European collaboration. INAF-IAPS (Italy) and the University of Oulu (Finland) maintain the ITACA ASCs and the ASC in Sodankylä. National Institute on Polar Research (Japan) is acknowledged for their service of auroral images which was used in RAF testing.

A. Ketola, L. Häkkinen, S. Mäkinen, P. Posio, K. Pajunpää and A. Koistinen (all in FMI Observation Unit) are acknowledged for their persistent and professional work for MIRACLE observations. P. Janhunen (FMI) gave valuable advice in the analysis of $W / V$ curves.

Edited by: J. Pulliainen

\section{References}

Amm, O., Donovan, E. F., Frey, H., Lester, M., Nakamura, R., Wild, J. A., Aikio, A., Dunlop, M., Kauristie, K., Marchaudon, A., McCrea, I. W., Opgenoorth, H.-J., and Strømme, A.: Coordinated studies of the geospace environment using Cluster, satellite and ground-based data: an interim review, Ann. Geophys., 23, 2129 2170, doi:10.5194/angeo-23-2129-2005, 2005.

Bala, R. and Reiff, P.: Validating the Rice neural network and the Wing Kp real-time models, Space Weather, 12, 417-425, doi:10.1002/2014SW001075, 2014.

Bartels, J., Heck, N. H., and Johnston, H. F.: The three-hour range index measuring geomagnetic activity, J. Geophys. Res., 44, 411-454, doi:10.1029/TE044i004p00411, 1939.

Finnish Meteorological Institute and University of Oulu: The AurorasNow! Service, Sodankylä Geophysical Observatory, http: //aurora.fmi.fi, last access: June 2016a.

Finnish Meteorological Institute, University of Oulu, University of Tromsö, Institute of Geophysics of the Polish Academy of Sciences, Polar Geophysical Institute (Russia), Swedish Institute of Space Physics, Geological Survey of Sweden, University of Tartu, Estonian Meteorological and Hydrological Institute, and National Institute of Astrophysics (Italy): http://space. fmi.fi/MIRACLE, last access: June 2016b.

Fukunishi, H., Toya, T., Koike, K., Kuwashima, M., and Kwamura, M.: Classification of hydromagnetic emissions based on frequency time spectra, J. Geophys., Res., 86, 9029-9039, 1981.

Gonzalez, W. D., Joselyn, J. A., Kamide, Y., Kroehl, H. W., Rostoker, G., Tsurutani, B. T., and Vasyliunas, V. M.: What is a geomagnetic storm? J. Geophys. Res., 99, 5771-5792, 1994.

Johnsen, M. G.: Real-time determination and monitoring of the auroral electrojet boundaries, J. Space Weather Space Clim., 3, A28, doi:10.1051/swsc/2013050, 2013.

Lilensten, J., Sanahuja, B., and Messerotti, M.: A European definition for Space Weather, in Developing the scientific basis for monitoring, modelling and predicting Space Weather, edited by: Lilensten, J., Belehaki, A., Messerotti, M., Vainio, R., Watermann, J., and Poedts, S., Office for Official Publications of the European Communities, Luxembourg, 302-305, 2008.

Mälkki, A., Kauristie, K., and Viljanen, A.: Auroras Now!, Final Report, Volume I, Finnish Meteorological Institute, Helsinki, 86 pp., 2006.

Nevanlinna, H. and Pulkkinen, T. I., Auroral observations in Finland: Results from all-sky cameras, 1973-1997, J. Geophys. Res., 106, 8109-8118, doi:10.1029/1999JA000362, 2001. 
NOAA - The US National Oceanic and Atmospheric Administration: OVATION auroral forecast, http://www.swpc.noaa.gov/ products/aurora-30-minute-forecast, last access: June 2016.

NOAA - The US National Oceanic and Atmospheric Administration: Space Weather Prediction Center, http://www.swpc.noaa. gov/ (last access: June 2016), 2016a.

NOAA - The US National Oceanic and Atmospheric Administration: Archive of alerts and warnings before 2015, NOAA Space Weather Prediction Center, http://legacy-www.swpc.noaa. gov/alerts/archive.html (last access: June 2016), 2016b.

Partamies, N., Juusola, L., Whiter, D., and Kauristie, K.: Substorm evolution of auroral structures, J. Geophys. Res., 120, 59585972, 2015.

Pulkkinen, A., Klimas, A., Vassiliadis, D., and Uritsky, V.: Role of stochastic fluctuations in the magnetosphere-ionosphere system: A stochastic model for the AE index variations, J. Geophys. Res., 111, A10218, doi:10.1029/2006JA011661, 2006.

Pulkkinen, T. I., Tanskanen, E. I., Viljanen, A., Partamies, N., and Kauristie, K.: Auroral electrojets during deep solar minimum at the end of solar cycle 23, J. Geophys. Res., 116, A04207, doi:10.1029/2010JA016098, 2011.

Rao, J., Partamies, N., Amariutei, O., Syrjäsuo, M., and van Sande, K. E. A.: Automatic Auroral Detection in Color All-Sky Camera Images, IEEE J. Select. Top. Appl. Earth Obs. Rem. S., 7, 47174725, doi:10.1109/JSTARS.2014.2321433, 2014.

Royal Observatory of Belgium: Solar Influences Data Center service in Belgia, http://sidc.oma.be/, last access: June 2016.

Seppinen, I. and Pellinen, R.: The history of Finnish Space Activities, Explorations, Studies in modern science and technology from the International Academy of the History of Science, Beauchesne Editeur, Paris, France, 203 pp., 2009.
Sigernes, F., Dyrland, M., Brekke, P., Chernouss, S., Lorentzen, D., Oksavik, K., and Deehr, C.: Two methods to forecast auroral display, J. Space Weather Space Clim. 1, A03, doi:10.1051/swsc/2011003, 2011.

Sigernes, F., Dyrland, M., Brekke, P., Chernouss, S., Lorentzen, D., Oksavik, K., and Deehr, C.: The Auroral forecast service at Kjell Henriksen Observatory (Svalbard, Norway), http://kho.unis.no, last acess: June 2016.

Starkov, G. V.: Mathematical model of the auroral boundaries, Geomag. Aeron., 34, 331-336, 1994.

Sucksdorff, C., Bösinger, T., Kangas, J., Mursula, K., Nygren T., Kauristie, K., and Koskinen, H.: Geophysics in Finland in the Twentieth Century, Geophysica, 37, 309-355, 2001.

Syrjäsuo, M. and Partamies, N.: Numeric features for detection aurora, IEEE Geosci. Remote Sens. Lett., 99, 1-4, doi:10.1109/LGRS.2011.2163616, 2011.

Ursa Astronomical Association: Finland, http://www.taivaanvahti. fi/observations/browse/list/1120892/observation_start_time, last access: June 2016.

Wing, S., Johnson, J. R., Jen, J., Meng, C.-I., Sibeck, D. G., Bechtold, K., Freeman, J., Costello, K., Balikhin, M., and Takahashi, K.: Kp forecast models, J. Geophys. Res., 110, A04203, doi:10.1029/2004JA010500, 2005.

Zhang, Y. and Paxton, L. J.: An empirical Kp-dependent global auroral model based on TIMED/GUVI data, J. Atmos. Sol.-Terr Phys., 70, 1231-1242, 2008. 